\title{
Calibration of the Interaction Parameters between the Proppant and Fracture Wall and the Effects of These Parameters on Proppant Distribution
}

\author{
Mingzhong Li ${ }^{1}$, Chunting Liu ${ }^{1, *}$ and Guodong Zhang ${ }^{2}$ \\ 1 College of Petroleum Engineering, China University of Petroleum (East China), Qingdao 266580, China; \\ lmzxinjiang@163.com \\ 2 College of Electromechanical Engineering, Qingdao University of Science and Technology, \\ Qingdao 266061, China; zhangguodong@qust.edu.cn \\ * Correspondence: Liuct.1990@hotmail.com; Tel.: +86-0546-8866398
}

Received: 4 February 2020; Accepted: 15 April 2020; Published: 23 April 2020

\begin{abstract}
Saltation and reputation (creep) dominate proppant transport rather than suspension during slickwater fracturing, due to the low sand-carrying capacity of the slickwater. Thus, the interaction parameters between proppants and fracture walls, which affect saltation and reputation, play a more critical role in proppant transport. In this paper, a calibration method for the interaction parameters between proppants and walls is built. A three-dimensional coupled computational fluid dynamics-discrete element method (CFD-DEM) model is established to study the effects of the interaction parameters on proppant migration, considering the wall roughness and unevenly distributed diameters of proppants. The simulation results show that a lower static friction coefficient and rolling friction coefficient can result in a smaller equilibrium height of the sand bank and a smaller build angle and drawdown angle, which is beneficial for carrying the proppant to the distal end of the fracture. The wall roughness and the unevenly distributed diameter of the proppants increase the collision between proppant and proppant or the wall, whereas the interactions have little impact on the sandbank morphology, slightly increasing the equilibrium height of the sandbank.
\end{abstract}

Keywords: interaction parameters; calibration method; coupled CFD-DEM model; wall roughness; unevenly distributed proppant diameter

\section{Introduction}

Slickwater is widely used during hydraulic fracturing in unconventional reservoirs to form complex fracture networks. It is used for its low cost and little damage it presents to reservoirs [1-6]. Proppants settle out of suspension more rapidly to form a bank in slickwater compared to conventional fracturing fluids, and the movement of the bank itself becomes an essential mechanism that dominates the proppant migration in the fracture [7]. As the proppant-proppant and proppant-wall interaction parameters affect the migration of the bedload layer, the study of the influences of the interaction parameters on proppant transport in slickwater is critical.

Experimental research over the years significantly contributed to our understanding of the mechanisms of proppant transport in low-viscosity fluids. Kern et al. [8] conducted the earliest work on slot flow experiments, and the results showed that the proppants would settle out of fluid and form a dune near the wellbore, and that proppants can be transported further into fractures only if the dune reaches the equilibrium height. More recent experimental works $[9,10]$ on proppant transport in slickwater confirmed similar findings to Kern et al. [8]. Furthermore, Woodworth et al. [11] used the results of laboratory experiments to analyze the influences of fluid viscosity, fluid density, pump rate, proppant size and density, proppant concentration, and fracture width on proppant transport in a 
low-viscosity fluid. Moreover, experiments on proppant transport in fracture networks $[10,12,13]$ were mostly carried out to answer the debatable question of whether slickwater can transport proppants into secondary fractures or not. In addition to experimental research, computational fluid dynamics (CFD) methods were widely used to study proppant transport in fractures. The most common approach for modeling proppant transport is the Eulerian-Eulerian method in which the interaction between the particles and fluid is fully coupled [14-19]. In a recent study, Han et al. [20] used the Eulerian granular model to track proppant movement in various fractures for a better understanding of how proppant transport is influenced by fracture viscosity, proppant density, and pump rate. The second method is the Eulerian-Lagrangian model, which tracks individual particle movement with time and location with the Lagrangian framework and describes fluid flow with the Eulerian framework [21-23]. The discrete element method (DEM) [24] is a useful tool to simulate the behavior of particles, and it can be coupled with CFD to model the interaction between particles and the surrounding fluid. In recent years, the coupled CFD-DEM model was used to study fracturing fluid flow in fractures for its advantages of considering proppant-proppant, proppant-boundary, and proppant-fracturing fluid interactions [25-32]. Blyton et al. [26] first used the coupled CFD-DEM model to simulate the motion of particles flowing with a fluid between fracture walls, and the simulations individually determined that particle trajectories such as particle-to-particle and particle-to-wall collisions occur. Zhang et al. [28] used a two-dimensional coupled CFD-DEM model to study the impacts of proppant diameter and density, fluid viscosity, and injection rate on proppant distribution. Kou et al. [31] used a three-dimensional coupled CFD-DEM model to investigate the effects of various proppant sizes and concentrations on bridging formation, and they quantified its impact by estimating the percentage of proppant reaching secondary fractures.

Although most of the numerical simulation studies on proppant transport in fractures considered the effects of the interaction between proppant and proppant or the wall, researchers stated the importance of the interaction parameters in two-phase flow [32,33], and the only work studying the effects of the interaction parameters on proppant distribution so far was conducted by Mack et al. [7]. As shown, the most critical proppant transport mechanisms in slickwater fracturing are saltation and reputation, and advanced ceramic proppants can be transported further into fractures as a result of the higher coefficient of restitution and a lower friction coefficient than other proppants. Furthermore, to the best of our knowledge, only the study of Mack et al. [7] calibrated some of the interaction parameters, including the friction coefficient and coefficient of restitution of the proppant, but without the interaction parameters between the proppant and wall.

Thus, in this paper, we intend to calibrate the interaction parameters between the proppant and proppant or the wall and study the effect of these parameters on proppant distribution in the fracture, considering the wall roughness and the uneven distribution of proppant size.

\section{Calibration of the Interaction Parameters}

The interaction parameters mainly include the static friction coefficient, rolling friction coefficient, and the coefficient of restitution. In this section, the interaction parameters between a conventional ceramic proppant and wall are measured. As the interaction parameters are related to the material, shape, and surface roughness of the proppant, and as they have little relationship with the particle size, a 20-40-mesh ceramic proppant is selected here as a research target for its large particle size, which is conducive to the experiments. A plexiglass plate, which is commonly used in experiments of proppant transport, and a cutting shale plate are selected here as research targets.

\subsection{Methods for Calibrating the Interaction Parameters between Proppant and Wall}

\subsubsection{Static Friction Coefficient between the Proppant and Wall}

Figure 1 shows the device for measuring the static friction coefficient between the proppant and wall. We fixed four proppant particles with the same diameter on a little glass plate (a) and placed the 
glass plate on the surface of either a plexiglass plate or a shale plate $(b)$, which can be raised on one side. We slowly lifted one side of (b) and recorded the angle $\alpha$ between (b) and the horizontal direction when the glass plate (a) began to slide due to gravity. We repeated the experiment five times and took the average value of the experimental results. The static friction coefficient between proppant and wall can be calculated as $\tan \alpha$.

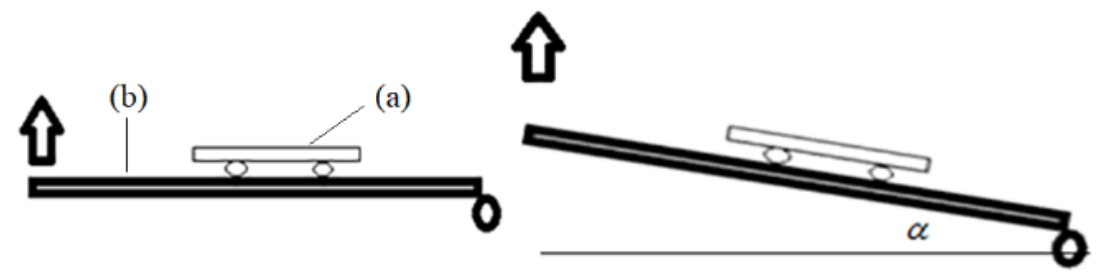

Figure 1. The experimental study on static friction coefficient between proppant and wall.

\subsubsection{Rolling Friction Coefficient between Proppant and Wall}

Figure 2 shows the device for measuring the rolling friction coefficient between the proppant and wall. Firstly, we balanced the upper glass plate (c) by placing three proppant particles (equilateral triangles) between plates (c) and (d). We connected the left side of the top plate (c) with a force sensor. We slowly pulled the lower plate $(\mathrm{d})$ to the right side at a constant speed, and the proppants began to move due to the tangential force of the lower plate (d). In the horizontal direction, the upper plate (c) was affected by the sliding friction force on the contact surface of the proppants and the horizontal binding force of the dynamometer. The proppants were in quasi-static equilibrium during the experiment.

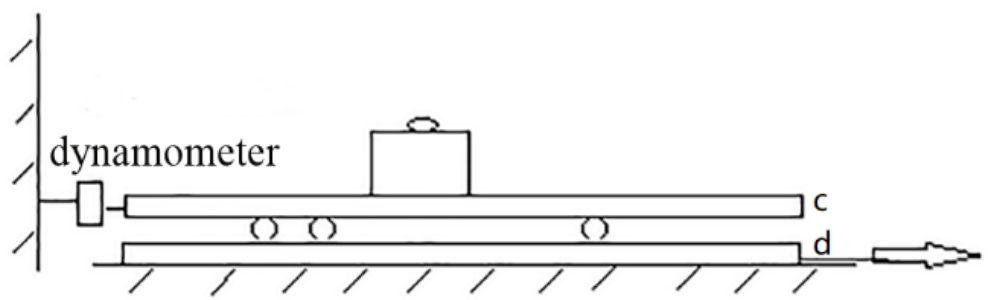

Figure 2. The experimental study on the rolling friction coefficient between proppant and wall.

Figure 3 shows the forces acting on proppant particles. $F_{s 1}$ and $F_{s 2}$ are the rolling friction forces on the upper and lower plates caused by the proppant, respectively. At the initial stage, as the tangential force increased, the proppants were in quasi-static equilibrium under the effect of the rolling friction torque and the rolling friction forces. Then, the proppants started to move from their rest position, affected by the increasing external force. The normal forces of the proppant acting on the upper and lower plates $\left(F_{n}\right)$ are equal when the weight of the proppant is neglected, and $F_{s 1}=F_{s 2}=F_{s}$ can be obtained by the balance equation of force when the proppants are in a stationary state or the critical state when the motion occurs. The friction torque between the proppant and the upper contact surface or the lower contact surface is equal because of the same contact condition when the proppants are regular spheres. The rolling friction coefficient can be calculated using Equation (1).

$$
u_{r}=\frac{F_{s}}{2 F_{n}}
$$

where $u_{r}$ is the rolling friction coefficient (dimensionless). 


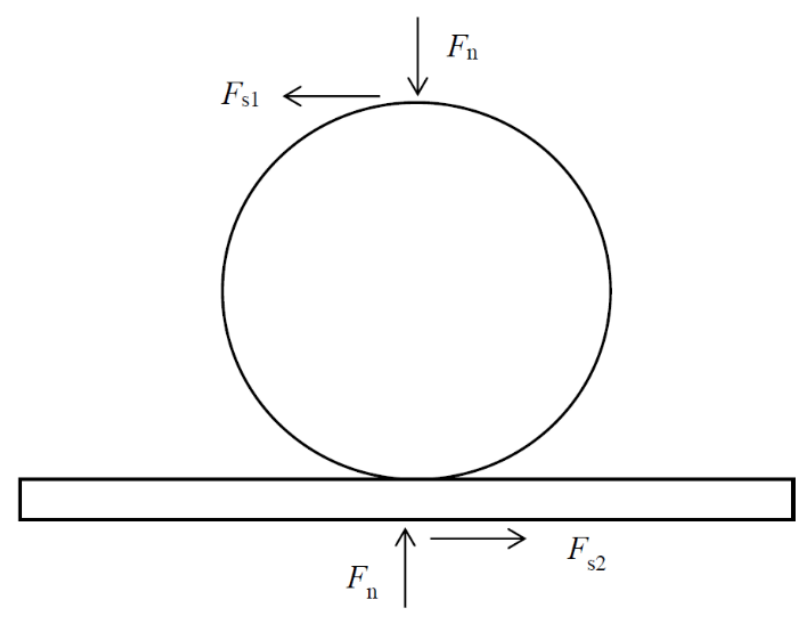

Figure 3. The forces acting on the proppant.

\subsubsection{Coefficient of Restitution}

The free-fall method is usually used to measure the coefficient of restitution. Mack et al. [7] used a 28-FPS (frames per second) video camera to record the proppant trajectory for measuring the maximum rebound height after the first collision between the proppant and wall. Since the equipment required with the free-fall method is expensive, a simple experimental device was used in this paper to measure the coefficient of restitution between the proppant and wall in air, and the coefficient of restitution in slickwater is $40 \%$ of the value in the air [34-36]. As shown in Figure 4, the angle between the plexiglass plate or the shale plate (a) and the horizontal direction was $45^{\circ}$. We let the proppant particle fall onto the surface (a) from a fixed initial height $(H)$, and then the proppant bounced onto the surface (b). We covered a layer of butter on the surface of the plate (b) to accurately record the collision position of proppant with the plate (b). We carried out experiments for the distance between the plate (b) and the collision position of the proppant with the plate (a), denoted as $H_{1}$ and $H_{2}$, respectively, and we measured the displacement of the proppant in the horizontal direction $\left(S_{1}\right.$ and $\left.S_{2}\right)$. The following formulae can be obtained without considering the effects of air resistance:

$$
\begin{gathered}
\left\{\begin{array}{c}
V_{0}=g t \\
H=\frac{1}{2} g t^{2}
\end{array} \rightarrow V_{0}=\sqrt{2 g H},\right. \\
\left\{\begin{array} { c } 
{ S _ { 1 } = V _ { x } t _ { 1 } } \\
{ S _ { 2 } = V _ { x } t _ { 2 } } \\
{ H _ { 1 } = V _ { y } t _ { 1 } + \frac { 1 } { 2 } g t _ { 1 } ^ { 2 } } \\
{ H _ { 2 } = V _ { y } t _ { 2 } + \frac { 1 } { 2 } g t _ { 2 } ^ { 2 } }
\end{array} \rightarrow \left\{\begin{array}{c}
V_{x}=\sqrt{\frac{g S_{1} S_{2}\left(S_{1}-S_{2}\right)}{2\left(H_{1} S_{2}-H_{2} S_{1}\right)}} \\
V_{y}=\frac{H_{1} V_{x}}{S_{1}}-\frac{g S_{1}}{2 V_{x}}
\end{array},\right.\right.
\end{gathered}
$$

where $V_{0}$ is the instantaneous velocity of the proppant before the proppant collides with the plate (a), given in $\mathrm{m} / \mathrm{s}$. $V_{x}$ and $V_{y}$ are the horizontal and vertical velocities of the proppant after the collision with the plate (a), respectively, given in $\mathrm{m} / \mathrm{s}$.

The coefficient of restitution is defined as the ratio of the normal relative velocity with which the particle leaves a collision to the normal relative velocity with which it enters the collision, and it can be calculated using Equation (4).

$$
e=\frac{V_{n}}{V_{n 0}}=\frac{\sqrt{V_{x}^{2}+V_{y}^{2}} \cdot \cos \left[45^{\circ}+\tan ^{-1}\left(\frac{V_{y}}{V_{x}}\right)\right]}{V_{0} \sin 45^{\circ}}
$$




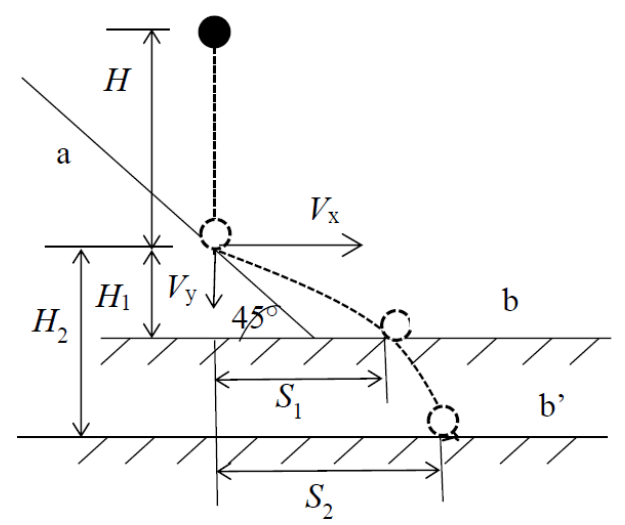

Figure 4. The experimental study on the coefficient of restitution between proppant and wall.

2.1.4. The Results of the Interaction Parameters between the Proppant and Wall

According to the above experiments, the interaction parameters between the proppant and wall could be obtained. The results are shown in Table 1.

Table 1. Results of the interaction parameters between the proppant and wall.

\begin{tabular}{ccccc}
\hline Case & $\boldsymbol{e}$ (air) & $\boldsymbol{e}$ (Slickwater) & $\mu_{\mathrm{s}}$ & $\mu_{\mathrm{r}}$ \\
\hline Proppant-plexiglass wall & 0.6 & 0.24 & 0.1944 & $6.5 \times 10^{-4}$ \\
Proppant-shale wall & 0.36 & 0.144 & 0.84 & 0.24 \\
\hline
\end{tabular}

$\mu_{\mathrm{s}}$ denotes the static friction coefficient.

\subsection{Interaction Parameters between Proppants}

The coefficient of restitution between proppants was not calculated in this paper, and the results of Mack et al. [7] were used, where $e$ (air) $=0.53$ and $e$ (slickwater) $=0.21$. Due to the tiny size of proppants, it was difficult to directly measure the static friction coefficient and the rolling friction coefficient between proppant particles in the experiments. Therefore, the angle of repose was studied by combining experiment and numerical simulation to obtain the friction coefficient between proppants.

(1) Experimental measurement of the angle of repose

The funnel method [37-40] and the hollow cylinder method (collapse test method) [41-43] are commonly used to measure the angle of repose of particles. In this study, the principle of the collapse test method was applied in the experimental device, shown in Figure 5. We put proppant particles with a height of $0.02 \mathrm{~m}$ into a cell made of plexiglass plates, and then quickly removed the baffle plate. The proppant began to move due to gravity until it stopped. Figure 6 shows the result. The angle of repose can be calculated using Equation (5), and the result was determined to be $24.22^{\circ}$.

$$
\alpha=\tan ^{-1} \frac{H}{L}
$$




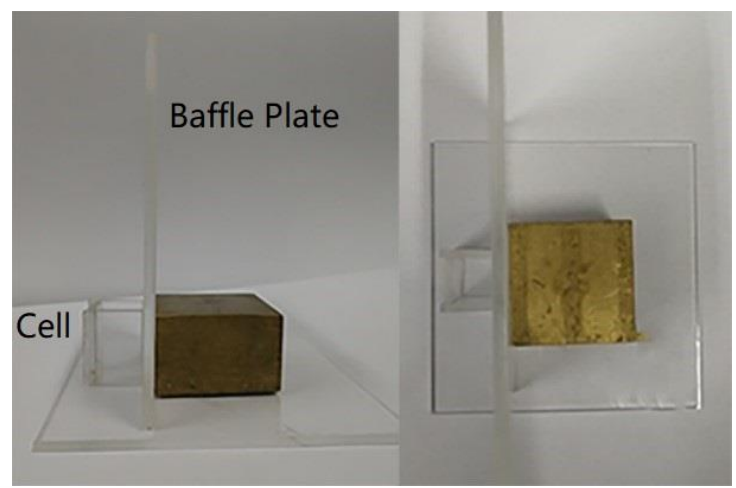

Figure 5. The experimental device for measuring the angle of repose.

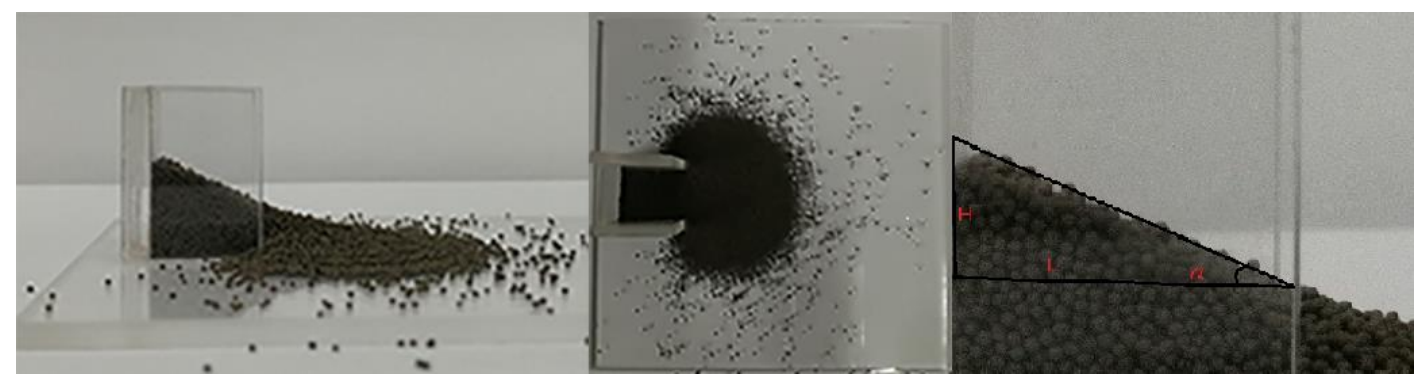

Figure 6. The experimental result of the angle of repose.

(2) Numerical simulation of the angle of repose

Using the median sieving diameter of the proppants may affect the simulation results because of the size difference of proppant of the same mesh. Therefore, in this study, the 20-40-mesh proppants were sieved into four groups, as shown in Table 2. We randomly selected 40 proppants from each group and measured the diameter of these proppants separately (average of length and width) with a microscope. The average diameter of the 40 proppants was taken as the actual particle diameter of the group. Figure 7 shows the linear relationship between the sieving diameter and the actual diameter of the proppants, and the actual proppant diameter can be calculated using Equation (6).

$$
d_{a}=0.9525 d_{s}+0.1253,
$$

where $d_{a}$ and $d_{s}$ are the actual diameter and sieving diameter of proppants, respectively, given in $\mathrm{m}$.

The mass fractions of the 20-40-mesh proppants in each group after sieving refinement are shown in Table 3, and the other essential parameters for the simulation are listed in Table 4.

Table 2. Proppant subdivision standard.

\begin{tabular}{ccccc}
\hline Group & $\mathbf{1}$ & $\mathbf{2}$ & $\mathbf{3}$ & $\mathbf{4}$ \\
\hline The sieving diameter $\left(10^{-6} \mathrm{~m}\right)$ & $425-500$ & $500-600$ & $600-710$ & $>710$ \\
\hline
\end{tabular}

Table 3. The mass fractions of the proppants in each group after sieving refinement.

\begin{tabular}{ccccc}
\hline Group & $\mathbf{1}$ & $\mathbf{2}$ & $\mathbf{3}$ & $\mathbf{4}$ \\
\hline Mass fraction $(\%)$ & 10 & 32 & 38 & 20 \\
\hline
\end{tabular}


Table 4. Parameters for the simulation.

\begin{tabular}{cc}
\hline Parameters & Value \\
\hline Proppant density $\left(\mathrm{kg} / \mathrm{m}^{3}\right)$ & 3223 \\
The density of plexiglass $\left(\mathrm{kg} / \mathrm{m}^{3}\right)$ & 1130 \\
The static friction coefficient between proppant and wall & 0.1944 \\
The rolling friction coefficient between proppant and wall & 0.00065 \\
The coefficient of restitution between proppants & 0.53 \\
\hline
\end{tabular}

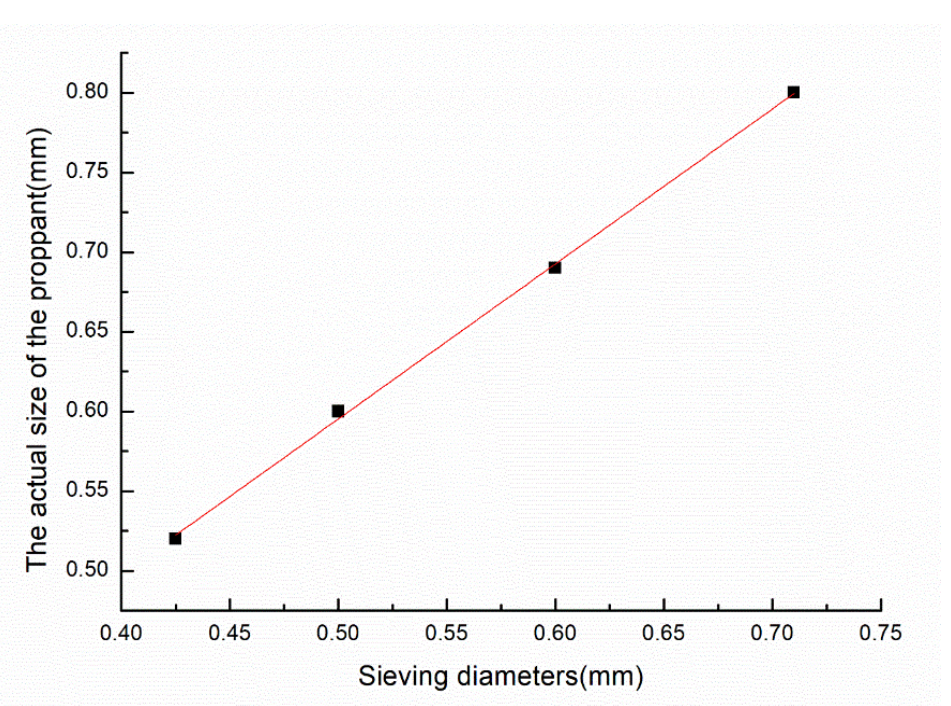

Figure 7. Comparisons of actual proppant diameters with sieving diameters.

Various static friction coefficients and rolling friction coefficients between proppants were preset, and the results are shown in Table 5. Figure 8 shows one simulation result of the angle of repose. By comparing the simulation results with the experimental results, the static friction coefficient and the rolling friction coefficient between proppants were 0.6 and 0.05 , respectively.

Table 5. Simulation results.

\begin{tabular}{ccccc}
\hline Case \# & $\begin{array}{c}\text { Static Friction } \\
\text { Coefficient } \\
\text { (Proppant-Proppant) }\end{array}$ & $\begin{array}{c}\text { Rolling Friction } \\
\text { Coefficient } \\
\text { (Proppant-Proppant) }\end{array}$ & $\begin{array}{c}\text { Angle of } \\
\text { Repose ( }{ }^{\circ} \text { ) }\end{array}$ & $\begin{array}{c}\text { The Difference in the } \\
\text { Angle of Repose with } \\
\text { Experimental Results (\%) }\end{array}$ \\
\hline 1 & 0.6 & 0.005 & 17.05 & 29.626878 \\
2 & 0.5 & 0.005 & 16.69 & 31.1127621 \\
3 & 0.4 & 0.005 & 15.99 & 34.0019812 \\
4 & 0.3 & 0.005 & 15.64 & 35.4465907 \\
5 & 0.6 & 0.01 & 18.43 & 23.9309889 \\
6 & 0.5 & 0.01 & 18.09 & 25.3343239 \\
7 & 0.4 & 0.01 & 17.74 & 26.7789335 \\
8 & 0.3 & 0.01 & 17.05 & 29.626878 \\
9 & 0.6 & 0.05 & 24.39 & -0.6686478 \\
10 & 0.5 & 0.05 & 23.75 & 1.9729239 \\
11 & 0.4 & 0.05 & 23.43 & 3.2937098 \\
12 & 0.3 & 0.05 & 23.11 & 4.6144956 \\
\hline
\end{tabular}




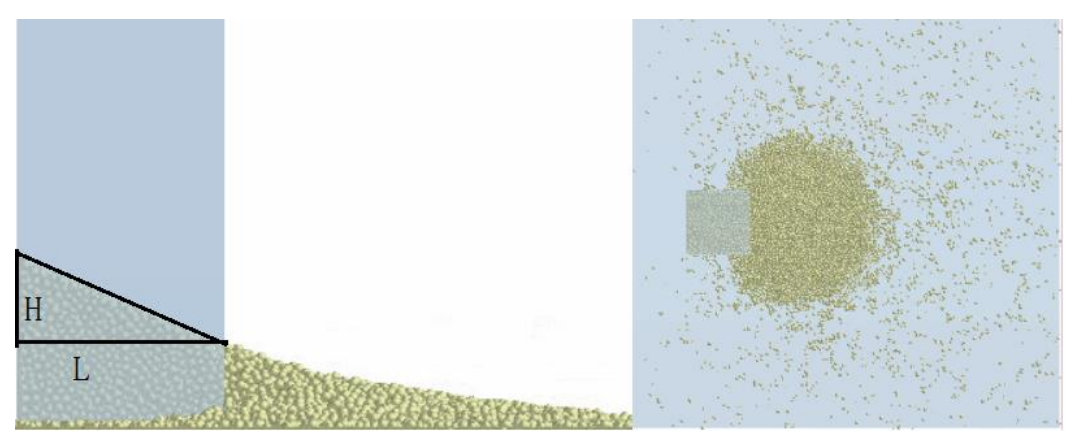

Figure 8. One simulation result of the angle of repose.

\section{Effects of the Interaction Parameters on Proppant Migration}

\subsection{Coupled CFD-DEM Model}

\subsubsection{Fluid Control Equations}

As a high displacement is generally used during slickwater fracturing, turbulence is the normal state of sand-carrying fluid, which is accounted for by using the standard $k-\varepsilon$ turbulence model $[19,30,44]$. Only the fluid phase is solved by the CFD code (Euler-Euler model) $[30,45]$.

(1) Mass conservation equation

$$
\frac{\partial}{\partial t}\left(\varepsilon_{f} \rho_{f}\right)+\nabla \cdot\left(\varepsilon_{f} \rho_{f} v_{f}\right)=0
$$

(2) Momentum conservation equation

$$
\frac{\partial}{\partial t}\left(\varepsilon_{f} \rho_{f} v_{f}\right)+\nabla \cdot\left(\varepsilon_{f} \rho_{f} v_{f} v_{f}\right)=-\varepsilon_{f} \nabla p+\varepsilon_{f} \nabla \cdot \tau_{f}+\varepsilon_{f} \rho_{f} g-\frac{1}{V_{c e l l}} \sum_{i=1}^{k} F_{d i} .
$$

Here, $\rho_{f}$ is the fluid density $\left(\mathrm{kg} / \mathrm{m}^{3}\right), \varepsilon_{f}$ is the volume fraction of the fluid in the computational cell (dimensionless), $v_{f}$ is the average velocity of a fluid cell $(\mathrm{m} / \mathrm{s}), t$ is the time $(\mathrm{s}), g$ is the acceleration due to gravity $\left(\mathrm{m} / \mathrm{s}^{2}\right), \tau_{f}$ is the fluid stress tensor $(\mathrm{N}), k$ is the number of particles in the corresponding fluid cell (dimensionless), and $F_{d i}$ is the force of the particles acting on the fluid (N).

\subsubsection{Particle Control Equations}

In the flow field, a variety of forces act on the particles, including the gravity force, collision contact force, buoyancy force, and drag force. The movement of particles is predominantly translational and rotational, and, according to Newton's second law, the expressions are given as Equations (9) and (10) [46].

$$
\begin{gathered}
m_{i} \frac{d v_{i}}{d t}=m_{i} g+\sum_{i=1}^{n} F_{c i}+F_{d i}+F_{b} \\
I_{i} \frac{d w_{i}}{d t}=\sum_{i=1}^{n} T_{i j},
\end{gathered}
$$

where $v_{i}$ is the translational velocity of particle $i(\mathrm{~m} / \mathrm{s}), w_{i}$ is the angular velocity of particle $i(\mathrm{rad} / \mathrm{s})$, $m_{i}$ is the mass of particle $i\left(\mathrm{~kg} / \mathrm{m}^{3}\right), I_{i}$ is the moment of inertia of the particle $i\left(\mathrm{~kg} \cdot \mathrm{m}^{2}\right), \sum_{i=1}^{n} F_{c i}$ is total contact force acting on particle $i(\mathrm{~N}), \sum_{i=1}^{n} T_{i j}$ is total torque acting on particle $i(\mathrm{~N} \cdot \mathrm{m}), F_{d i}$ is the drag force 
of the fluid acting on particle $(\mathrm{N}), F_{b}$ is the buoyancy force $(\mathrm{N})$, and $n$ is the number of total contacts for the particle $i(\mathrm{~N})$.

The collisions between particle and particle or the boundaries are critical parts in the solid-liquid two-phase flow. In this paper, we apply the Hertz-Mindlin (no slip) model $[30,47,48]$ to analyze the particle moving pattern.

$$
F_{c i}=F_{c n i}+F_{c t i}+F_{d n i}+F_{d t i}
$$

where $F_{c n i}$ and $F_{c t i}$ are the contact forces along the normal and tangential directions, respectively $(\mathrm{N})$. Terms $F_{d n i}$ and $F_{d t i}$ are the damping forces in the normal and tangential directions, respectively $(\mathrm{N})$.

$$
\begin{gathered}
F_{c n i}=\frac{4}{3} E^{*}\left(R^{*}\right)^{1 / 2} \alpha^{3 / 2}, \\
\frac{1}{E^{*}}=\frac{1-v_{1}^{2}}{E_{1}}+\frac{1-v_{2}^{2}}{E_{2}}, \\
R^{*}=\frac{1}{R_{1}}+\frac{1}{R_{2}}
\end{gathered}
$$

where $E^{*}$ is the effective Young's modulus $\left(\mathrm{N} / \mathrm{m}^{2}\right), R^{*}$ is the effective particle radius $(\mathrm{m}), \alpha$ is the displacement of the amount of normal overlap $(\mathrm{m}), E_{1}$ and $E_{2}$ are the Young's moduli of particles 1 and 2 , respectively $\left(\mathrm{N} / \mathrm{m}^{2}\right), v_{1}$ and $v_{2}$ are the Poison ratios of particles 1 and 2, respectively (dimensionless), and $R_{1}$ and $R_{2}$ denote the radii of particles 1 and 2, respectively (m).

$$
\begin{gathered}
F_{d n i}=-2 \sqrt{\frac{5}{6} \lambda \sqrt{S_{n} m^{*}} v_{n}^{r e l},} \\
m^{*}=\frac{m_{1} m_{2}}{m_{1}+m_{2}}, \\
\lambda=\frac{\ln e}{\sqrt{\ln ^{2} e+\pi^{2}}}, \\
S_{n}=2 E^{*} \sqrt{R^{*} \alpha}, \alpha=R_{1}+R_{2}-\overrightarrow{r_{1}}-\overrightarrow{r_{2}}, \\
v_{n}^{r e l}=\left(\overrightarrow{v_{1}}-\overrightarrow{v_{2}}\right) \cdot \vec{n}, \vec{n}=\frac{\overrightarrow{r_{1}}-\overrightarrow{r_{2}}}{\left|\overrightarrow{r_{1}}-\overrightarrow{r_{2}}\right|},
\end{gathered}
$$

where $m^{*}$ is the equivalent mass $(\mathrm{kg}), S_{n}$ is the stiffness in the normal direction $(\mathrm{N} / \mathrm{m}), v_{n}^{r e l}$ is the component of relative velocity in the normal direction $(\mathrm{m} / \mathrm{s}), m$ is the mass of the particle $(\mathrm{kg}), e$ is the coefficient of restitution (dimensionless), $\vec{v}$ is the particle velocity before the collision (m/s), $\vec{n}$ is the normal unit vector at collision (dimensionless), and $\overrightarrow{r_{1}}$ and $\overrightarrow{r_{2}}$ are the position vectors of the two ball centers, respectively $(\mathrm{m} / \mathrm{s})$.

$$
\begin{gathered}
F_{c t i}=-S_{t} \zeta_{,} \\
S_{t}=8 G^{*} \sqrt{R^{*} \alpha}, G^{*}=\frac{2-v_{1}^{2}}{G_{1}}+\frac{2-v_{2}^{2}}{G_{2}},
\end{gathered}
$$

where $S_{t}$ is the stiffness in the tangential direction $(\mathrm{N} / \mathrm{m}), \zeta$ is the overlap in the tangential direction $(\mathrm{m}), G^{*}$ is the effective shear modulus $(\mathrm{Pa})$, and $G_{1}$ and $G_{2}$ are the shear moduli of particles 1 and 2, respectively $(\mathrm{Pa})$.

$$
F_{d t i}=-2 \sqrt{\frac{5}{6}} \lambda \sqrt{S_{n} m^{*}} v_{t}^{r e l}, v_{t}^{r e l}=\left(\overrightarrow{v_{1}}-\overrightarrow{v_{2}}-v_{n}^{r e l}\right) \cdot \vec{n},
$$

where $v_{t}^{r e l}$ is the relative velocity in the tangential direction $(\mathrm{m} / \mathrm{s})$. 
The rolling friction is essential in the simulation and can be illustrated by the torque on the friction surface using Equation (23).

$$
T_{i j}=-\mu_{r} F_{c n i} R_{i} \vec{w}_{i}
$$

where $\mu_{r}$ is the rolling friction coefficient (dimensionless), $R_{i}$ is the distance between the mass center and the contact point $(\mathrm{m})$, and $\vec{W}_{i}$ denotes the unit angular velocity vector of the object at the point of contact.

The calculation of the drag forces of the fluid acting on the particles is significant for the coupling of the CFD and DEM parts.

$$
F_{d i}=\frac{V \beta}{\varepsilon_{s}}\left(\overrightarrow{v_{s}}-\overrightarrow{v_{f}}\right)
$$

where $V$ is the volume of the proppant particles $\left(\mathrm{m}^{3}\right), \beta$ given by the Gidaspow drag model $\left(\mathrm{kg} /\left(\mathrm{m}^{3} \cdot \mathrm{s}\right)\right)[27$, 49], as per Equation (25), and the fluid-particle drag coefficient $C_{D}$ (dimensionless) can be calculated using Equation (26).

$$
\begin{gathered}
\beta=\left\{\begin{array}{l}
150 \frac{\varepsilon_{s}^{2} \mu_{f}}{\varepsilon_{f} d_{p}^{2}}+1.75 \frac{\rho_{f} \varepsilon_{s}\left|\vec{v}_{s}-\vec{v}_{f}\right|}{d_{p}} \text { when } \varepsilon_{f} \leq 0.8, \\
\frac{3}{4} C_{D} \frac{\rho_{f} \varepsilon_{s}\left|\vec{v}_{s}-\vec{v}_{f}\right|}{d_{p}} \varepsilon_{f}^{-1.65} \text { when } \varepsilon_{f}>0.8
\end{array}\right. \\
C_{D}=\left\{\begin{array}{l}
\frac{24}{\varepsilon_{f} \operatorname{Re}_{s}}\left[\begin{array}{c}
1+0.15\left(\varepsilon_{f} \operatorname{Re}_{s}\right)^{0.687} \\
0.44
\end{array}\right] \text { when } \operatorname{Re}_{s} \geq 1000 \\
\operatorname{Re}_{s}<1000
\end{array},\right.
\end{gathered}
$$

where $\varepsilon_{f}$ and $\varepsilon_{s}$ denote the volume fraction of fluid and particles, respectively (dimensionless), and $\mu_{f}$ is the fluid viscosity $(\mathrm{Pa} \cdot \mathrm{s})$.

\subsubsection{Initial and Boundary Conditions}

Figure 9 shows the geometric model of the vertical well and the horizontal well, and the size of the fracture model was $0.25 \mathrm{~m}(\mathrm{~L}) \times 0.006 \mathrm{~m}(\mathrm{~W}) \times 0.05 \mathrm{~m}(\mathrm{H})$.

(a)

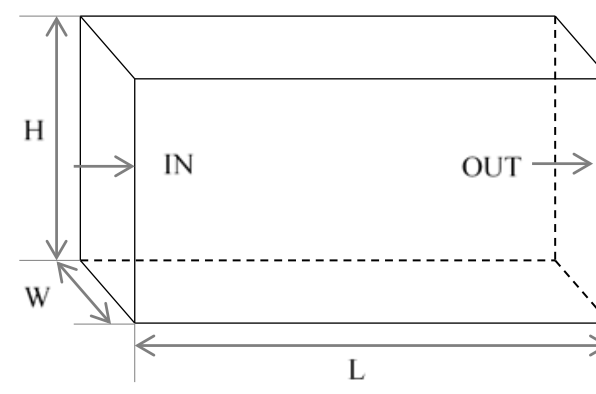

(b)

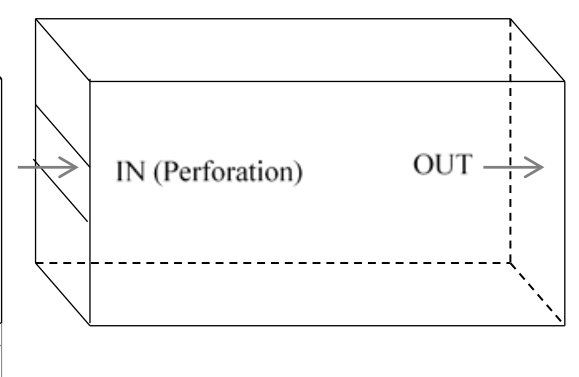

Figure 9. The geometric model: (a) vertical well, (b) horizontal well.

(1) CFD initial and boundary conditions

Fluid flowed from the inlet (IN) to the outlet (OUT). For the horizontal well, the location of the perforation was in the middle of the left boundary, and the size of the perforation was $0.006 \mathrm{~m} \times 0.006 \mathrm{~m}$. We applied a velocity boundary and a constant pressure boundary on the inlet and outlet, respectively. The boundaries in the $y$-direction and $z$-direction were rigid walls with the no-slip condition.

(2) DEM initial and boundary conditions

Randomly located particles were created through the particle factory, which was built at the inlet boundary, at a fixed rate, to ensure a constant concentration of injected particles. Furthermore, the injected particles had the same horizontal speed as the injected fluid. 
(3) Coupling of CFD and DEM

We set the timestep of the CFD and DEM solver. The timestep used in the DEM solver was $5 \times 10^{-6} \mathrm{~s}$ ( $21 \%$ of the Rayleigh times), and the timestep used in the CFD solver was $5 \times 10^{-4} \mathrm{~s}$. The data exchange for coupling the CFD and DEM solver mainly includes three steps:

- Solving the pressure and velocity fields of the liquid phase with the CFD part without considering the particles.

- The velocities of particles are exerted on the CFD grid blocks where they are "covered" by the particles. As a result of this process, the flow field violates the conservation of mass requirements and is corrected to ensure this condition is once more satisfied.

- The force exerted on each particle by the fluid is calculated and sent to the DEM code.

\subsection{Mechanisms of Proppant Transport in the Fracture}

The mechanisms of proppant transport in the low-viscosity fluid along the fracture were studied first. The proppant-proppant and proppant-wall interaction parameters are shown in Table 6, and the other necessary settings in the simulation are shown in Table 7. As the mechanisms of the proppant migration are only analyzed in this section, the proppant diameter and sand ratio were bigger than those used during fracturing to reduce the time cost in the simulation, and this did not affect the mechanism of proppant migration.

Table 6. The interaction parameters between proppant and fracture wall.

\begin{tabular}{cccc}
\hline Parameters & $\begin{array}{c}\text { Coefficient of } \\
\text { Restitution }\end{array}$ & $\begin{array}{c}\text { Static Friction } \\
\text { Coefficient }\end{array}$ & $\begin{array}{c}\text { Rolling Friction } \\
\text { Coefficient }\end{array}$ \\
\hline Proppant-proppant & 0.21 & 0.6 & 0.05 \\
Proppant-wall & 0.24 & 0.1944 & 0.005 \\
\hline
\end{tabular}

Table 7. Necessary parameters in the simulation.

\begin{tabular}{cccc}
\hline Parameters & Value & Parameters & Value \\
\hline Injection rate & $0.3 \mathrm{~m} / \mathrm{s}$ & Fracturing fluid viscosity & $1 \mathrm{mPa} \cdot \mathrm{s}$ \\
Particle diameters & $1.4 \mathrm{~mm}$ & Sand ratio & $20 \%$ \\
\hline
\end{tabular}

According to actual real-life hydraulic fracturing, the injection rate is about $2-6 \mathrm{~m}^{3} / \mathrm{min}, W=0.006 \mathrm{~m}, H=20 \mathrm{~m}$; then, in the initial stage of fracturing, the velocity of the fracturing fluid in the fracture will be in the range of $0.26-1$ $\mathrm{m} / \mathrm{s}$. The injection rate in the simulation can reflect the actual flow rate of the fracturing fluid.

Figures 10 and 11 show the phenomenon of proppant transport in the fracture of the vertical well and horizontal well, respectively. As can be seen from them, whether for the vertical or for the horizontal well, in the early stage, the proppants settled down rapidly near the wellbore under the action of gravity and formed the proppant dune because of the low viscosity of the fracture fluid, and the suspension was the primary mechanism of proppant migration. With the injection of the fracturing fluid, a bedload layer formed on the surface of the proppant due to the dragging effects of the fracturing fluid on proppants, and the flow rate of the fracturing fluid increased with the decrease of the flow area in the upper part of the sand bed. Therefore, the drag force acting on the surface of the sand bed increased until the height of the sand bed stopped increasing to reach the equilibrium height, and the build angle and the drawdown angle were also maintained constant. The proppants were transported to the distal end of the fracture. At this stage, fluidization and resuspension at the distal end of the sand bed dominated the proppant migration. Due to the erosion of the fracturing fluid, a sizeable non-filled area formed near the wellbore, which influenced the hydraulic fracturing as a consequence. The study of proppant migration mechanisms showed that bedload transport was the main form of proppant transport during slickwater fracturing, and the process of proppant 
migration with saltation and creep can be shown in Figure 12. The mass flux of the creeping layer can be expressed as per Equation (21) [50,51].

$$
Q_{\text {creep }}=\frac{\rho_{f}^{2}}{2 \rho_{s} \bar{\varepsilon} g \mu_{m}^{2}} \sqrt{\frac{\mu_{m}-\mu_{d}}{c d_{p} g}} \cdot U_{*}^{4},
$$

where $Q_{\text {creep }}$ is the mass flux of the creeping layer per unit width $(\mathrm{kg} /(\mathrm{s} \cdot \mathrm{m})), \rho_{s}$ is the density of the proppant $\left(\mathrm{kg} / \mathrm{m}^{3}\right), \bar{\varepsilon}$ is the volume fraction of the proppant in the creep layer (dimensionless), $\mu_{m}$ and $\mu_{d}$ are the coefficient of static friction and coefficient of rolling friction between the proppant, respectively (dimensionless), $U_{*}$ is the shear velocity of the fluid acting on the creeping layer $(\mathrm{m} / \mathrm{s})$, and $c$ is a constant of 1.5 .
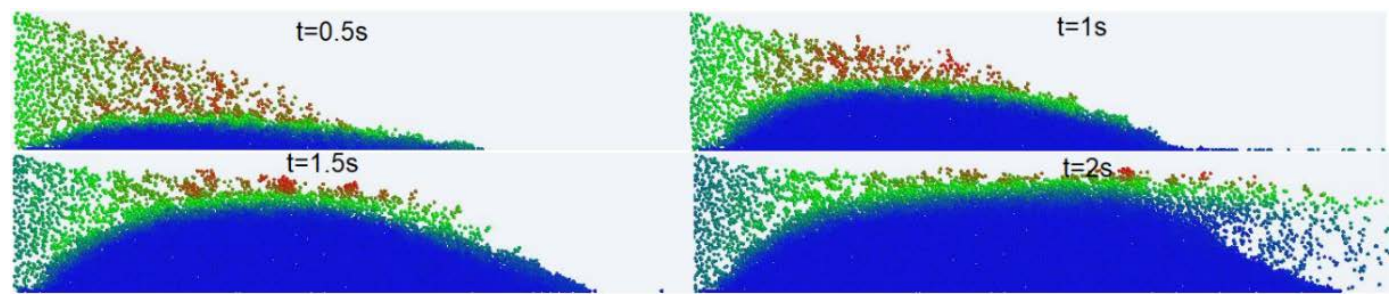

Figure 10. Distribution of proppants along with fracture slot of the vertical well.

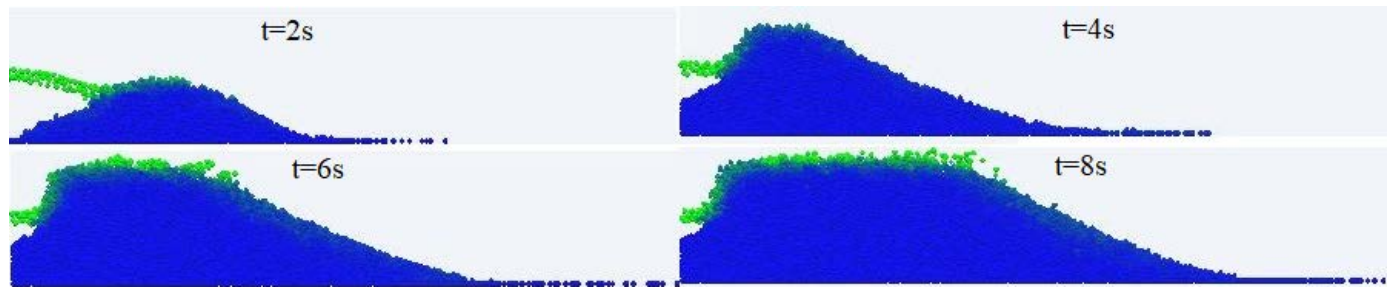

Figure 11. Distribution of proppants along with fracture slot for horizontal well.

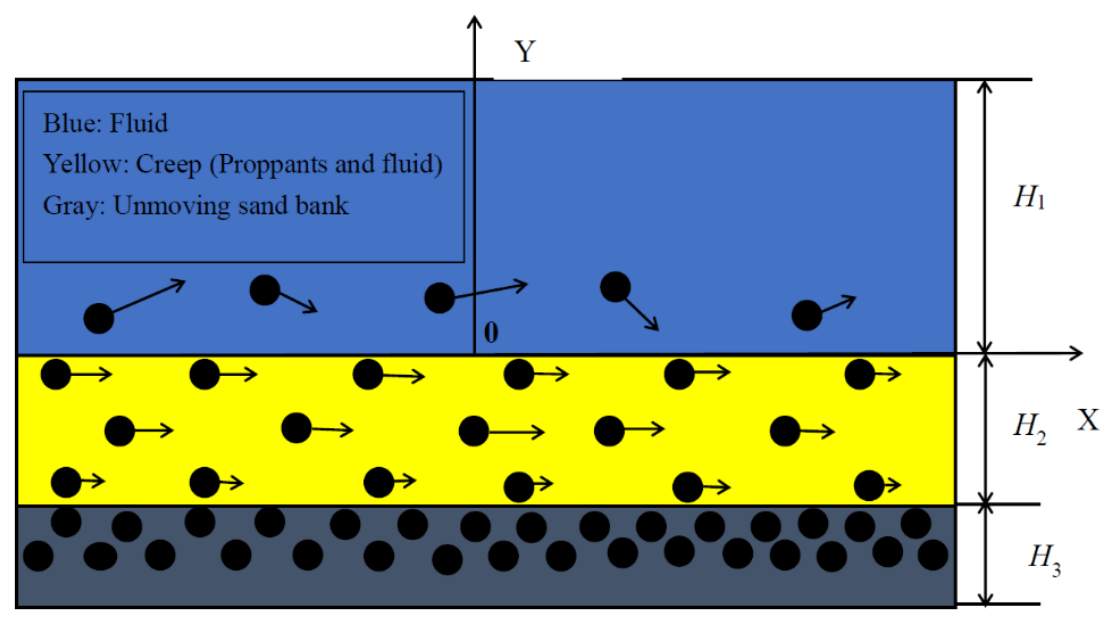

Figure 12. Illustration of proppant migration with saltation and creeping.

As can be seen from Equation (27), the coefficient of static friction and the coefficient of rolling friction between proppants affect the mass flux of the creeping layer, which further affect the distribution of proppants in the fracture. Moreover, the interaction between the proppant and fracture walls can also affect the migration in the fracture. Therefore, it is significant to calibrate the parameters of the proppant-proppant and proppant-wall interactions. Figure 13 shows the surface morphology of the sand bed with time, through which the growth process of the sand bed can be better observed. 

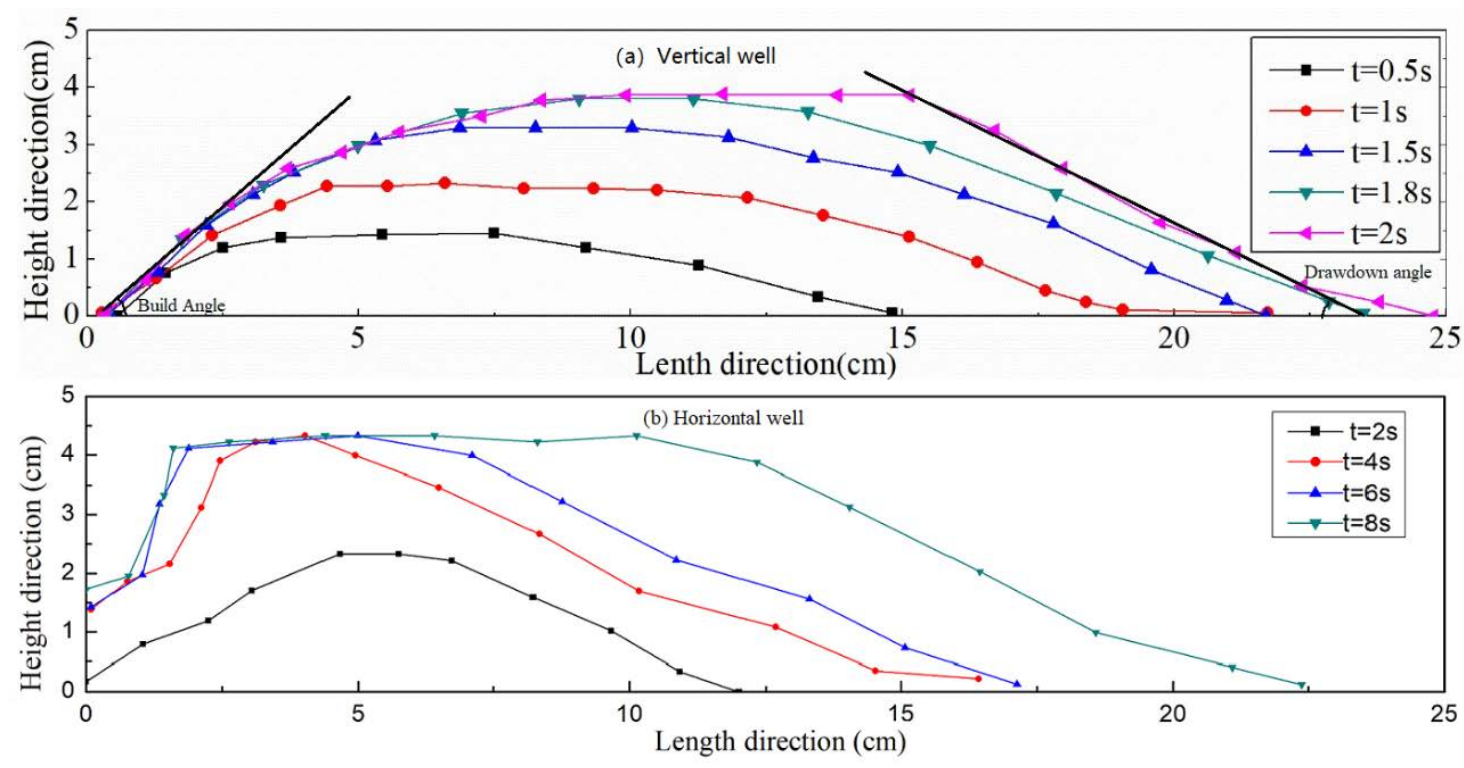

Figure 13. The growing process of proppant dune: (a) vertical well, (b) horizontal well.

\subsection{Effects of Interaction Parameters on Proppant Distribution in the Fracture}

The wall roughness and the uneven distribution of proppant diameter increase the interaction between proppants and walls, and the interaction parameters between the proppants and walls affect the sand bed morphology. Therefore, in this section, the effects of the interaction parameters of the proppants and walls on proppant distribution are studied, considering the wall roughness and unevenly distributed proppant diameter. As can be seen from the previous study, the mechanism of proppant migration in fractures of vertical or horizontal wells is the same. Therefore, fracture of vertical wells was analyzed when studying the influence of interaction parameters on proppant migration. The underlying simulation parameters are listed in Table 7 . The rough fracture model was established based on the experiment data of Barton $(J R C=10)$ [52], as shown in Figure 14. Table 8 shows the contact parameters of different cases for the simulation. Case 2 had a larger coefficient of restitution than case 1, while the static friction coefficient and rolling friction coefficient of the two models were the same. Case 3 had a larger static friction coefficient and rolling friction coefficient of proppant-proppant and proppant-wall interaction than case 1, while the coefficients of restitution of the two models were the same.

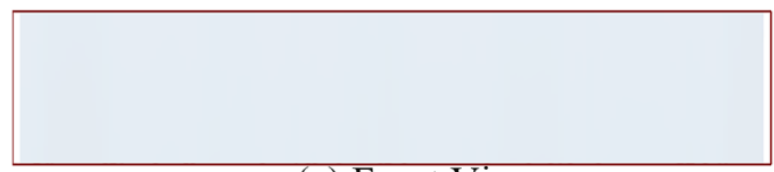

(a) Front View

(b) Top View

Figure 14. Morphology of the rough fracture $(J R C=10)$. 
Table 8. The contact parameters of different models.

\begin{tabular}{ccccccc}
\hline \multirow{2}{*}{ Case } & \multicolumn{2}{c}{ The Contact Parameters (Proppant-Proppant) } & \multicolumn{2}{c}{ The Contact Parameters (Proppant-Wall) } \\
\cline { 2 - 7 } & $\begin{array}{c}\text { Coefficient of } \\
\text { Restitution }\end{array}$ & $\begin{array}{c}\text { Static } \\
\text { Friction } \\
\text { Coefficient }\end{array}$ & $\begin{array}{c}\text { Rolling } \\
\text { Friction } \\
\text { Coefficient }\end{array}$ & $\begin{array}{c}\text { Coefficient of } \\
\text { Restitution }\end{array}$ & $\begin{array}{c}\text { Static } \\
\text { Friction } \\
\text { Coefficient }\end{array}$ & $\begin{array}{c}\text { Rolling } \\
\text { Friction } \\
\text { Coefficient }\end{array}$ \\
\hline 1 & 0.21 & 0.6 & 0.05 & 0.24 & 0.19 & 0.005 \\
2 & 0.27 & 0.6 & 0.05 & 0.31 & 0.3 & 0.005 \\
3 & 0.21 & 0.8 & 0.1 & 0.24 & 0.26 & 0.01 \\
\hline
\end{tabular}

(1) The sand bed morphology with single-diameter proppants

Figure 15 shows the distribution of single-diameter proppants in a smooth fracture, and, as can be seen, the coefficient of restitution had little effect on the equilibrium height, build angle, and drawdown angle due to less interaction between the proppant and proppant or the wall. When the static friction coefficient and the rolling friction coefficient were smaller, the equilibrium height, build angle, and drawdown angle of the sand bank were lower, enabling the proppants to be transported into the distal end of the fracture. When the sandbank reached the equilibrium height, all the proppant injected could be calculated as the bedload layer. From Equation (27), it can be calculated that the shear velocity of the fluid acting on the sandbank in case 3 was 1.1236 times that of the shear velocity in case 1. Therefore, the equilibrium height of the sandbank in case 3 would be higher than that in case 1 for a higher shear velocity.
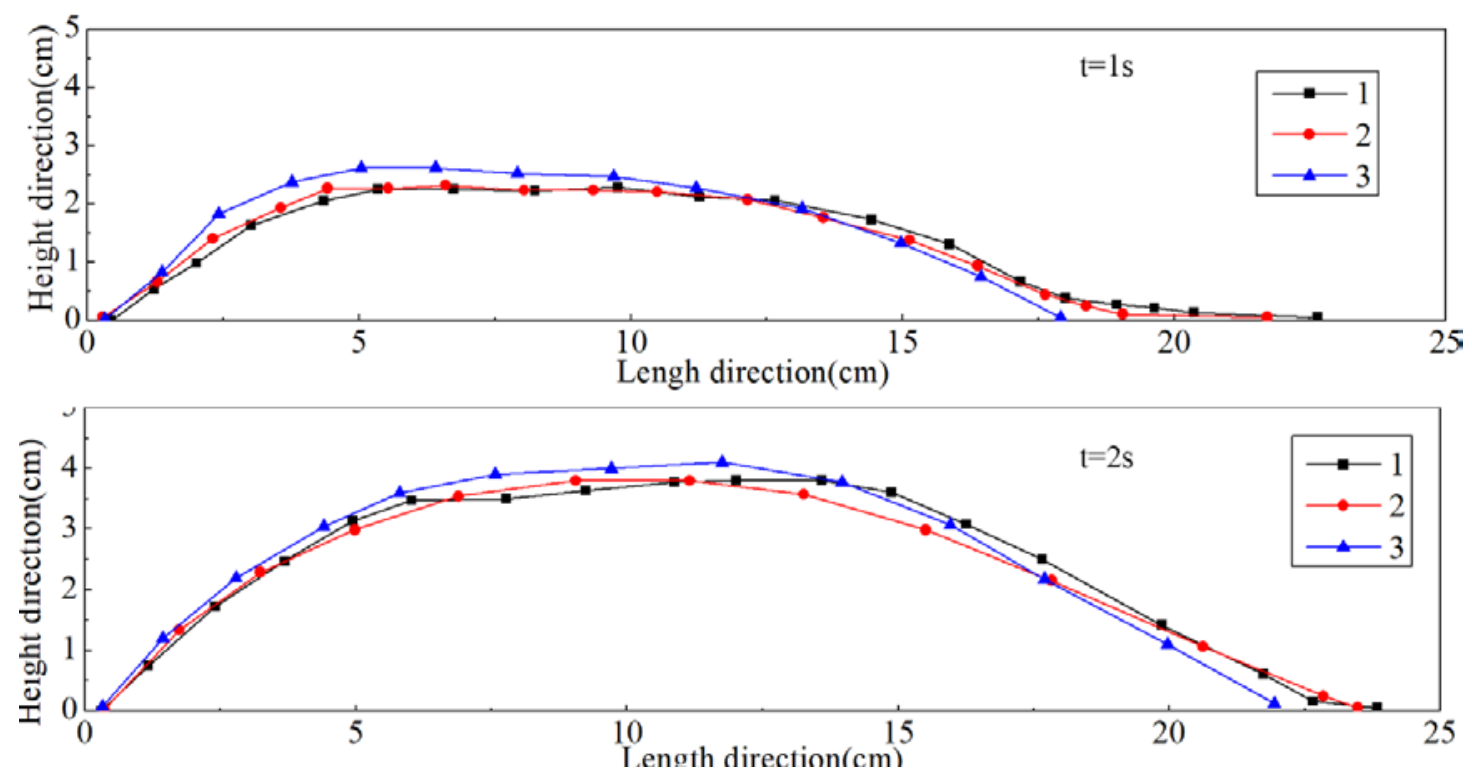

Figure 15. The distribution of single-sized proppants in smooth fracture.

(2) The effects of a rough fracture on proppant distribution

Figure 16 shows the distribution of proppants with a single diameter in smooth and rough fractures. As shown, the roughness of the fracture had little effect on proppant distribution, and the equilibrium height of the sandbank in the rough fracture was slightly larger than that in the smooth fracture, while the build and the drawdown angles were similar. This result indicates that the interaction between the proppants and walls had little impact on the morphology of the sandbank, although the wall roughness increased proppant-proppant and proppant-wall collisions. 


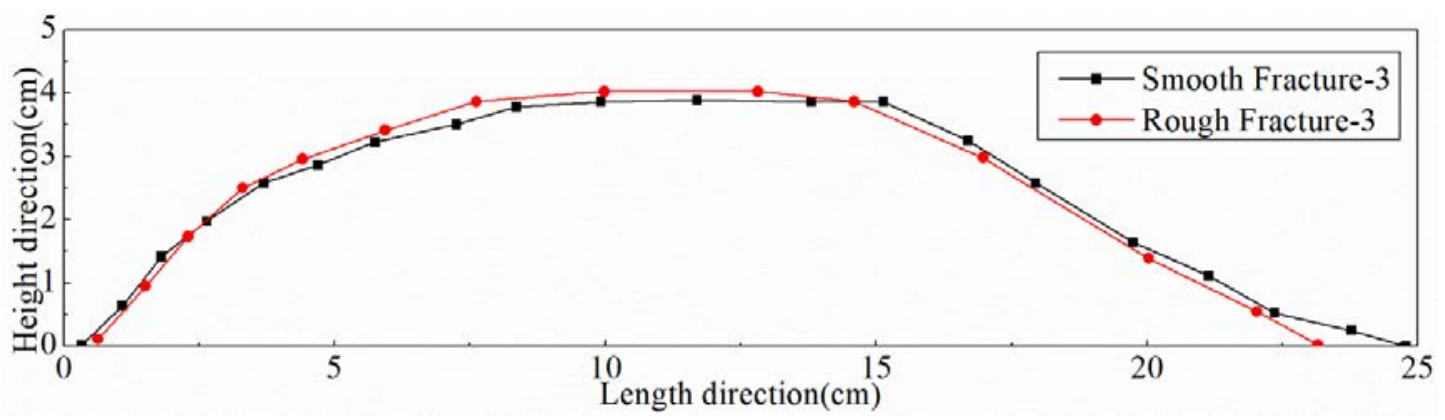

Figure 16. Comparison of proppant distribution in smooth and rough fracture $(t=2 \mathrm{~s})$.

(3) The effects of an unevenly distributed proppant diameter on proppant distribution

Figure 17 shows the comparison of the distribution of proppants with a single diameter and proppants with a normally distributed diameter in fractures. In the early stage of the injection, the nonuniformity of the proppant size increased the interaction between the suspended particles and made the particle movement more complicated. However, when the sandbank reached the equilibrium height, the primary mechanisms which dominated the proppant migration were fluidization and resuspension at the distal end of the fracture. Thus, the proppant-proppant collision and proppant-wall collision had little impact on proppant distribution, slightly increasing the equilibrium height of the sandbank, while they had no influence on the buildup and drawdown angles.

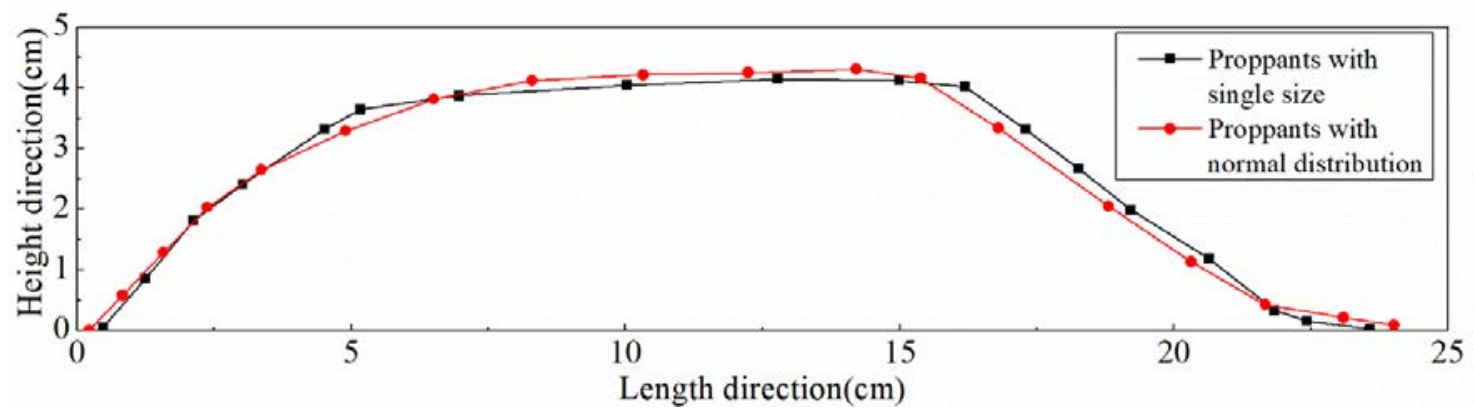

Figure 17. Comparison of the distribution of single-sized proppants and proppants with normal size distribution $(t=2 \mathrm{~s})$.

\section{Discussion}

In conventional fracturing fluids, the mechanism of proppant transport is mainly suspension, and most of the proppant remains in suspension until the fracture is reclosed. Thus, the study of proppant transport is mostly about the settling velocity of proppants in fracturing fluids with various viscosities, and the wall-retardation effect is also a significant research direction. As the interactions between the proppant and proppant or the wall affect the settling velocity and horizontal velocity of the proppant, and since the sand ratio and unevenly distributed diameter of the proppant increase the complexity of suspended proppant movement, the proppant distribution in the fracture will be greatly influenced by the interactions. Since the coupled CFD-DEM model used in this paper greatly reduced the calculation efficiency with the increase in the number of particles, a small fracture size was used in the simulation, and the proppant was in suspension for a short time. Therefore, although the results obtained in this paper show little effect of the fracture roughness and unevenly distributed diameter of the proppant on proppant distribution, this result only reflects the effects of the factors on bedload proppant transport but without the suspension proppant transport. In slickwater, the proppant settles out of suspension near the wellbore rapidly to form a dune, and the bedload layer becomes the main patten of proppant transport. Thus, we believe that the study of the settling velocity and wall retardation is not as important as the bedload proppant transport affected by various factors 
during slickwater hydraulic fracturing. Thus, the effects of the interaction parameters on suspended proppant transport are no longer conducted here.

Many researchers $[7,11,28,30]$ studied the effects of various factors, including the proppant diameter, proppant density, the viscosity of the fracturing fluid, injection rate, and sand ratio on the proppant distribution and equilibrium height of the sand bank. However, they did not consider the effects of the interaction parameters. However, from the research in this paper, we can see that, when the sandbank reaches the equilibrium height, the shear stress of the fluid acting on the bedload layer needed for carrying the injected proppant to the further end of the fracture will increase with an increase of the static friction coefficient and rolling friction coefficient between proppants, and this will lead to the increase in the equilibrium height of the sandbank. The experimental results of Mack et al. [7] also showed similar results. As shown, advanced ceramic proppants can be transported further into fractures as a result of the higher coefficient of restitution and a lower friction coefficient than conventional ceramic proppant and sand. However, many of the bedload transport models, including the model used in the paper of Mack et al. [7], cannot consider the influence of interaction parameters, although the experimental and numerical simulation results show that the interaction parameters have an impact on the bedload proppant transport and proppant distribution. Thus, it is of great significance to calibrate the interaction parameters between proppant and further studies on the bedload proppant transport for further study of the proppant distribution in the fracture during slickwater hydraulic fracturing.

As can be seen from the study above, the impacts of proppant physical parameters on suspended proppant transport and bedload proppant transport should be considered when selecting the proppant during slickwater hydraulic fracturing. Moreover, further research and discussion can be done. In this paper, the influences of the interaction parameters on suspended proppant transport were not studied, and the effects of the interaction parameters on proppant migration were analyzed only from the phenomena observed, but not quantitatively analyzed. All the factors that affect the movement of the bedload layer will affect the equilibrium height of the sand bank, such as the injection rate, the density of the proppant, density of the fluid, rolling friction coefficient, static friction coefficient, and so on. To the best of our knowledge, the equations for calculating the equilibrium height of the sandbank cannot consider the influence of all of the factors. Thus, in future research, we will establish a new model for calculating the equilibrium height based on the analysis of the forces acting on the bedload layer, and we will make some progress by doing so.

\section{Conclusions}

In this paper, a method for calibrating the interaction parameters between proppant and proppant or the wall was proposed. The coupled CFD-DEM model was established considering the interaction between proppants and walls to study the mechanisms of proppant transport in fracture and to analyze the impacts of the interaction parameters on proppant distribution considering the wall roughness and unevenly distributed diameter of proppants. The following conclusions can be drawn from the research:

(1) A lower static friction coefficient and rolling friction coefficient between the proppant and proppant or the wall can result in a smaller equilibrium height of sandbank and a smaller build angle and drawdown angle, which is beneficial for transporting the proppant to the distal end of fractures.

(2) The wall roughness increases the collision between the proppant and proppant or the wall, whereas the interactions have little impacts on the sandbank morphology. Wall roughness slightly increases the equilibrium height of the sandbank, while it does not have any influence on the build angle or drawdown angle.

(3) In the early stage of fracturing, an uneven particle size increases the complexity of the movement of the suspended proppant. However, when the sand bed reaches the equilibrium height, it has little impact on the sandbank morphology, only slightly increasing the equilibrium height. 
Author Contributions: Conceptualization, M.L. and C.L.; data curation, G.Z.; formal analysis, C.L.; funding acquisition, M.L. and G.Z.; project administration, M.L.; software, C.L.; supervision, M.L.; validation, C.L.; writing-original draft, C.L.; writing-review and editing, G.Z. All authors read and agreed to the published version of the manuscript.

Funding: This research was funded by the National Natural Science Foundation of China (grant number 51804175).

Acknowledgments: The authors also thank the anonymous reviewers for useful comments.

Conflicts of Interest: The authors declare no conflicts of interest.

\section{References}

1. Gu, M.; Dao, E.; Mohanty, K.K. Investigation of ultra-light weight proppant application in shale fracturing. Fuel 2015, 150, 191-201. [CrossRef]

2. Naval, G.; Shah, S. A Rheological Criterion for Fracturing Fluids to Transport Proppant during a Stimulation Treatment. In Proceedings of the SPE Annual Technical Conference and Exhibition, New Orleans, LA, USA, 30 September-3 October 2001; Society of Petroleum Engineers: Richardson, TX, USA, 2001.

3. Gu, M.; Kulkarni, P.M.; Rafiee, M.; Ivarrud, E.; Mohanty, K.K. Understanding the Optimum Fracture Conductivity for Naturally Fractured Shale and Tight Reservoirs. In Proceedings of the SPE/CSUR Unconventional Resources Conference, Calgary, AB, Canada, 30 September-2 October 2014; Society of Petroleum Engineers: Richardson, TX, USA, 2014.

4. Wu, K.; Olson, J.E. Numerical Investigation of Complex Hydraulic Fracture Development in Naturally Fractured Reservoirs. In Proceedings of the SPE Hydraulic Fracturing Technology Conference, The Woodlands, TX, USA, 3-5 February 2015; Society of Petroleum Engineers: Richardson, TX, USA, 2016.

5. Taherdangkoo, R.; Tatomir, A.; Taylor, R.; Sauter, M. Numerical investigations of upward migration of fracking fluid along a fault zone during and after stimulation. Energy Procedia 2017, 125, 126-135. [CrossRef]

6. Taherdangkoo, R.; Tatomir, A.; Anighoro, T.; Sauter, M. Modeling fate and transport of hydraulic fracturing fluid in the presence of abandoned wells. J. Contam. Hydrol. 2019, 221, 58-68. [CrossRef]

7. Mack, M.; Sun, J.; Khadilkar, C. Quantifying Proppant Transport in Thin Fluids: Theory and Experiments. In Proceedings of the SPE Hydraulic Fracturing Technology Conference, The Woodlands, TX, USA, 4-6 February 2014; Society of Petroleum Engineers: Richardson, TX, USA, 2014.

8. Kern, L.R.; Perkins, T.K.; Wyant, R.E. The Mechanics of Sand Movement in Fracturing. J. Petrol. Technol. 1959, 11, 55-57. [CrossRef]

9. Barree, R.D. Experimental and numerical modeling of convective proppant transport. J. Petrol. Technol. 1995, 47, 216-222. [CrossRef]

10. Sahai, R.; Miskimins, J.L.; Olson, K.E. Laboratory Results of Proppant Transport in Complex Fracture Systems. In Proceedings of the SPE Hydraulic Fracturing Technology Conference, The Woodlands, TX, USA, 4-6 February 2014; Society of Petroleum Engineers: Richardson, TX, USA, 2014.

11. Woodworth, T.R.; Miskimins, J.L. Extrapolation of Laboratory Proppant Placement Behavior to the Field in Slickwater Fracturing Applications. In Proceedings of the SPE Hydraulic Fracturing Technology Conference, College Station, TX, USA, 29-31 January 2007; Society of Petroleum Engineers: Richardson, TX, USA, 2007.

12. Alotaibi, M.A.; Miskimins, J.L. Slickwater Proppant Transport in Complex Fractures: New Experimental Findings \& Scalable Correlation. In Proceedings of the SPE Annual Technical Conference and Exhibition, Houston, TX, USA, 28-30 September 2015; Society of Petroleum Engineers: Richardson, TX, USA, 2015.

13. Li, N.; Li, J.; Zhao, L.; Luo, Z.; Liu, P.; Guo, Y. Laboratory Testing on Proppant Transport in Complex-Fracture Systems. SPE Prod. Oper. 2017, 32, 382-391. [CrossRef]

14. Mobbs, A.T.; Hammond, P.S. Computer Simulations of Proppant Transport in a Hydraulic Fracture. SPE Prod. Oper. 2001, 16, 112-121. [CrossRef]

15. Adachi, J.; Siebrits, E.; Peirce, A.; Desroches, J. Computer simulation of hydraulic fractures. Int. J. Rock Mech. Min. Sci. 2007, 44, 739-757. [CrossRef]

16. Weng, X.; Kresse, O.; Cohen, C.E.; Wu, R.; Gu, H. Modeling of Hydraulic-Fracture-Network Propagation in a Naturally Fractured Formation. SPE 140253 PA 2011, 26, 368-380. [CrossRef]

17. Dontsov, E.V.; Peirce, A. Proppant Transport in Hydraulic Fracturing: Crack Tip Screen-Out in KGD and P3D Models; The University of British Columbia: Vancouver, BC, Canada, 2014. [CrossRef] 
18. Kong, X.; McAndrew, J. A Computational Fluid Dynamics Study of Proppant Placement in Hydraulic Fracture Networks. In Proceedings of the SPE Unconventional Resources Conference, Calgary, AL, Canada, 15-16 February 2017; Society of Petroleum Engineers: Richardson, TX, USA, 2017.

19. Yang, R.; Guo, J.; Zhang, T.; Zhang, X.; Ma, J.; Li, Y. Numerical Study on Proppant Transport and Placement in Complex Fractures System of Shale Formation Using Eulerian Multiphase Model Approach. In Proceedings of the International Petroleum Technology Conference, Beijing, China, 26-28 March 2019; IPTC: Richardson, TX, USA, 2019.

20. Han, J.; Yuan, P.; Huang, X.; Zhang, H.; Sookprasong, A.; Li, C.; Dai, Y. Numerical Study of Proppant Transport in Complex Fracture Geometry. In Proceedings of the SPE Low Perm Symposium, Denver, CO, USA, 5-6 May 2016; Society of Petroleum Engineers: Richardson, TX, USA, 2016.

21. Tsai, K.; Degaleesan, S.S.; Fonseca, E.R.; Lake, E. Advanced Computational Modeling of Proppant Settling in Water Fractures for Shale Gas Production. In Proceedings of the SPE Hydraulic Fracturing Technology Conference, The Woodlands, TX, USA, 6-8 February 2012; Society of Petroleum Engineers: Richardson, TX, USA, 2012.

22. Snider, D.M. An Incompressible Three-Dimensional Multiphase Particle-in-Cell Model for Dense Particle Flows. J. Comput. Phys. 2001, 170, 523-549. [CrossRef]

23. Snider, D.; Banerjee, S. Heterogeneous gas chemistry in the CPFD Eulerian-Lagrangian numerical scheme (ozone decomposition). Powder Technol. 2010, 199, 100-106. [CrossRef]

24. Rahmati, H.; Jafarpour, M.; Azadbakht, S.; Nouri, A.; Vaziri, H.; Chan, D.; Xiao, Y. Review of Sand Production Prediction Models. J. Petrol. Eng. 2013, 2013. [CrossRef]

25. Zeng, J.; Li, H.; Zhang, D. Numerical simulation of proppant transport in hydraulic fracture with the upscaling CFD-DEM method. J. Nat. Gas Sci. Eng. 2016, 33, 264-277. [CrossRef]

26. Blyton, C.A.J.; Gala, D.P.; Sharma, M.M. A Comprehensive Study of Proppant Transport in a Hydraulic Fracture. In Proceedings of the SPE Annual Technical Conference and Exhibition, Houston, TX, USA, 28-30 September 2015; Society of Petroleum Engineers: Richardson, TX, USA, 2015.

27. Tomac, I.; Gutierrez, M. Micromechanics of proppant agglomeration during settling in hydraulic fractures. J. Petrol. Explor. Prod. Technol. 2015, 5, 417-434. [CrossRef]

28. Zhang, G.; Gutierrez, M.; Li, M. Numerical simulation of transport and placement of multi-sized proppants in a hydraulic fracture in vertical wells. Granul. Matter 2017, 19, 1-15. [CrossRef]

29. Kou, R.; Moridis, G.J.; Blasingame, T.A. Analysis and Modeling of Proppant Transport in Inclined Hydraulic Fractures. In Proceedings of the SPE Hydraulic Fracturing Technology Conference and Exhibition, The Woodlands, TX, USA, 23-25 January 2018; Society of Petroleum Engineers: Richardson, TX, USA, 2018.

30. Baldini, M.; Carlevaro, C.M.; Pugnaloni, L.A.; SáNchez, M. Numerical simulation of proppant transport in a planar fracture. A study of perforation placement and injection strategy. Int. J. Multiph. Flow 2018, 109, 207-218. [CrossRef]

31. Kou, R.; Moridis, G.; Blasingame, T. Bridging Criteria and Distribution Correlation for Proppant Transport in Primary and Secondary Fracture. In Proceedings of the SPE Hydraulic Fracturing Technology Conference and Exhibition, The Woodlands, TX, USA, 5-7 February 2019; Society of Petroleum Engineers: Richardson, TX, USA, 2019.

32. Zhang, G.; Gutierrez, M.; Li, M. A coupled CFD-DEM approach to model particle-fluid mixture transport between two parallel plates to improve understanding of proppant micromechanics in hydraulic fractures. Powder Technol. 2017, 308, 235-248. [CrossRef]

33. Goniva, C.; Kloss, C.; Deen, N.G.; Kuipers, J.A.; Pirker, S. Influence of rolling friction on single spout fluidized bed simulation. Particuology 2012, 10, 582-591. [CrossRef]

34. Mack, M.G.; Coker, C.E. Proppant Selection for Shale Reservoirs: Optimizing Conductivity, Proppant Transport and Cost. In Proceedings of the SPE Unconventional Resources Conference Canada, Calgary, AL, Canada, 5-7 November 2013; Society of Petroleum Engineers: Richardson, TX, USA, 2013.

35. Joseph, G.G.; Zenit, R.; Hunt, M.L.; Rosenwinkel, A.M. Particle-wall collisions in a viscous fluid. J. Fluid Mech. 2001, 433, 329-346. [CrossRef]

36. Joseph, G.; Hunt, M. Oblique particle-wall collisions in a liquid. J. Fluid Mech. 2004, 510, 71-93. [CrossRef]

37. Coetzee, C.J.; Els, D.N.J. Calibration of granular material parameters for DEM modelling and numerical verification by blade-granular material interaction. J. Terramech. 2009, 46, 15-26. [CrossRef] 
38. Jin, F.; Xin, H.; Zhang, C.; Sun, Q. Probability-based contact algorithm for non-spherical particles in DEM. Powder Technol. 2011, 212, 134-144. [CrossRef]

39. Geer, S.; Bernhardt-Barry, M.; Garboczi, E.; Whiting, J.; Donmez, A. A more efficient method for calibrating discrete element method parameters for simulations of metallic powder used in additive manufacturing. Granul. Matter 2018, 20, 1-17. [CrossRef]

40. Ucgul, M.; Fielke, J.M.; Saunders, C. Defining the effect of sweep tillage tool cutting edge geometry on tillage forces using 3D discrete element modelling. Inf. Process. Agric. 2015, 2, 130-141. [CrossRef]

41. Salawu, A.T.; Suleiman, M.L.; Isiaka, M. Physical Properties of Jatropha curcas Seed. Electronic Journal of Polish Agricultural Universities. Available online: http://www.ejpau.media.pl/volume16/issue4/art-07.html (accessed on 13 December 2013).

42. Lajeunesse, E.; Mangeney-Castelnau, A.; Vilotte, J. Spreading of a granular mass on a horizontal plane. Phys. Fluids 2004, 16, 2371-2381. [CrossRef]

43. Al-Hashemi, H.; Baghabra Al-Amoudi, O. A review on the angle of repose of granular materials. Powder Technol. 2018, 330, 397. [CrossRef]

44. Versteeg, H.K.; Malalasekera, W. An Introduction to Computational Fluid Dynamics: The Finite Volume Method; Pearson Education: London, UK, 2007.

45. Hobbs, A. Simulation of an aggregate dryer using coupled CFD and DEM methods. Int. J. Comput. Fluid Dyn. 2009, 23, 199-207. [CrossRef]

46. Wang, Y.; Ai, J. Coupled CFD-DEM Simulation of Upward Seepage Flow in Granular Media. In Proceedings of the The Twenty-fifth International Ocean and Polar Engineering Conference, Kona, HI, USA, 21-26 June 2015; Society of Petroleum Engineers: Richardson, TX, USA, 2015.

47. Herzt, H. Ueber die Beruhrrung fester elastischer Korper. J. Reine Angew. Math. 1881, 92, 156-171.

48. Mindlin, R.D.; Deresiewicz, H. Elastic Spheres in Contact Under Varying Oblique Forces. J. Appl. Mech. Asme 1953, 20, 327-344.

49. Tsuo, Y.P.; Gidaspow, D. Computation of flow patterns in circulating fluidized beds. AIChE J. 1990, 36, 885-896. [CrossRef]

50. Wang, Z.T.; Zheng, X.J. Theoretical prediction of creep flux in aeolian sand transport. Powder Technol. 2004, 139, 123-128. [CrossRef]

51. Chang, O.; Kinzel, M.; Dilmore, R.; Wang, J.Y. Physics of Proppant Transport Through Hydraulic Fracture Network. J. Energy Res. Technol. 2018, 140, 032912. [CrossRef]

52. Barton, N.; Choubey, V. The shear strength of rock joints in theory and practice. Rock Mech. 1977, 10, 1-54. [CrossRef]

(C) 2020 by the authors. Licensee MDPI, Basel, Switzerland. This article is an open access article distributed under the terms and conditions of the Creative Commons Attribution (CC BY) license (http://creativecommons.org/licenses/by/4.0/). 